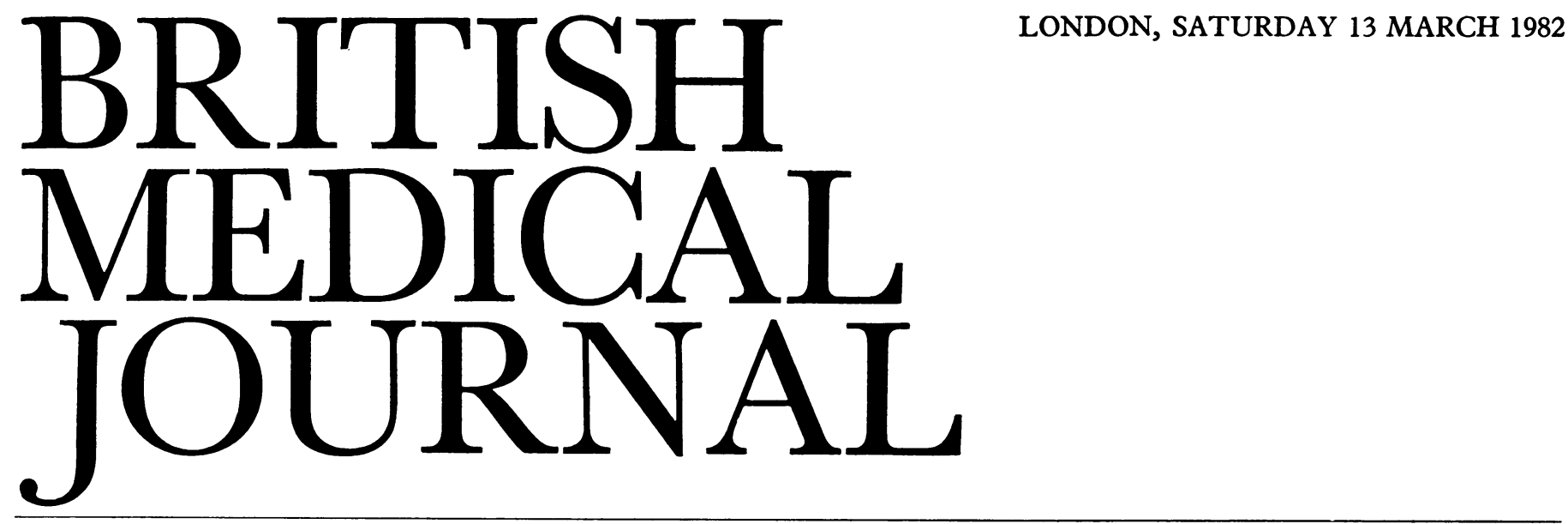

Fashions in drug usage change, just as they do in other topics. Sometimes the change may even have a logical basis-and the use of vasodilators for the treatment of heart failure is such an example.

First suggested in 1944 as a rational treatment for pulmonary oedema, ${ }^{1}$ vasodilators had to wait for acceptable methods of bedside haemodynamic monitoring before their place in routine medical care could be defined accurately. Recent technical advances have, indeed, transformed our approach to the management of heart failure, which for so many years was dominated by digitalis. Chronic heart failure can now be managed by therapeutic manipulation of the venous circulation, the myocardial pump itself, or the arteriolar vasculature.

This new physiological approach requires an understanding of the changes that occur in haemodynamics of heart failure. The cause of heart failure is usually diminished contractility of the left ventricle, owing either to direct myocardial damage (as in ischaemic heart disease) or to chronic pressure or volume overload (as in hypertension or valvular heart disease). An early response of the heart to decreased contractility is ventricular dilatation. In haemodynamic terms left ventricular dilatation is measured as an increase in left ventricular enddiastolic volume. This dilatation can be considered according to Starling's law as a compensatory mechanism to maintain stroke volume.

A second response of the failing circulation is a reflex increase in sympathetic tone and the production of angiotensin, which increases the heart rate, cardiac contractility, and peripheral vascular resistance-the last being an attempt to maintain arterial pressure to perfuse vital circulations such as those of the heart and brain. Both these compensatory mechanisms will eventually fail if the underlying disorder progresses. At first the failure will be clinically manifest only on exercise but later at rest as well.

What, then, are the advantages and drawbacks of the various approaches to the treatment of heart failure? The long-term value of the stimulation of the failing myocardium by digitalis glycosides has come under severe criticism in recent years, though Chatterjee and his colleagues have recently provided a spirited rebuttal, documenting an impressive improvement of cardiac function by long-term treatment with digoxin. ${ }^{2}$ The use of cardiac beta-adrenoceptor stimulants such as prenalterol remains a largely experimental but nevertheless interesting approach. ${ }^{3}$ Dopamine ${ }^{4}$ and dobutamine, ${ }^{5}$ both effective inotropic agents, can be used only in the short term since they need to be given parenterally. The second approach is by modification of the peripheral circulation. Diuretics will remain a sheet anchor of treatment, because they enhance the excretion of sodium and water, thus decreasing ventricular preload. The other tool to modify the peripheral circulation is vasodilatation.

Appropriate drug treatment can dilate either the arteriolar or venous side of the circulation (or both). Vasodilators that relax the peripheral arteriolar bed will diminish the increased resistance against which the ventricle must empty, resulting in an increase in cardiac output. As a bonus, the improvement in pump performance produced by arteriolar vasodilators is accompanied by a reduction in myocardial oxygen consumption, since both systolic pressure and heart size are reduced. ${ }^{6}$ (In contrast, inotropic agents increase arterial pressure and the velocity of the shortening of the cardiac muscle fibres and tend to raise myocardial oxygen consumption. ${ }^{6}$ ) A hypothetical drawback of the use of an arteriolar vasodilator is that it might cause an unacceptable fall in arterial blood pressure. If left ventricular function were normal this might indeed happen, but the more abnormal the function of the left ventricle the greater the rise in stroke volume and cardiac output as the aortic impedance is reduced, thus lessening any unwanted fall in arterial pressure. ?

Drugs that dilate the postcapillary venous capacitance beds cause a redistribution of intravascular blood volume from the central to the peripheral reservoirs-in other words, venous pooling. Again, the haemodynamic results differ in the normal and compromised heart. In normal circumstances venous pooling results in a diminution of stroke output and a compensatory rise in heart rate; but in heart failure diminution of venous return will reduce cardiac filling pressures and relieve the signs of raised pulmonary capillary pressure. ${ }^{7}$ Though the main sites of action of all vasodilators are on the peripheral circulation, they may also act to reduce segmental myocardial ischaemia, perhaps by increasing collateral blood flow. ${ }^{8}$ Furthermore, the compliance of the left ventricular musculature may be increased, though the underlying mechanism remains obscure. ${ }^{9}$

Vasodilators can be classified according to their principal peripheral vascular effects. ${ }^{7}$ Only those that may be given by mouth are of use in chronic heart failure. Glyceryl trinitrate and the organic nitrates (for example, isosorbide dinitrate) exert their effects via dilatation of the smooth muscle in the veins and much less in the arterioles. Hydralazine, minoxidil, and the calcium antagonist nifedipine dilate predominantly the precapillary arteriolar bed while sparing venous capacitance vessels. A third group of drugs dilate both arteriolar and venous beds. Prazosin blocks postsynaptic alpha-adrenoceptors 
in arterioles and veins. Captopril, which inhibits the conversion of angiotensin I to angiotensin II and is now widely used as an antihypertensive agent, is also a vasodilator of the veins and arteries and is undergoing trials in heart failure in Britain. Nitroprusside, which is available only for parenteral administration and so is used only in acute heart failure, also dilates vessels on both sides of the circulation.

There are two main clinical indications ${ }^{10}$ for treatment of heart failure with vasodilators. Firstly, in acute myocardial infarction, where parenteral administration is frequently necessary, vasodilators may improve pump function, thus lessening pulmonary oedema, and perhaps diminish the area of ischaemic injury. Nevertheless, morphine remains the drug of choice in pulmonary oedema. Secondly, in chronic congestive heart failure refractory to digitalis and diuretics judicious administration of vasodilators may produce remarkably beneficial results.

The choice of vasodilator is determined by the patient's symptoms and signs and by haemodynamic considerations. When the symptoms of pulmonary venous congestion are present and the pulmonary capillary wedge pressure is raised venous dilators such as the nitrates are indicated. When the predominant symptoms in heart failure are tiredness and fatigue and measurements show a decrease in cardiac output and an increased systemic vascular resistance an arteriolar dilator such as hydralazine is more appropriate. If the cardiac output is decreased and the pulmonary capillary wedge pressure is raised, which is probably the commonest finding, a balanced vasodilator such as prazosin may be used.

Nevertheless, several problems are associated with using vasodilators in heart failure. The patient must definitely be in heart failure before the drugs are given and an accurate profile of haemodynamic measurements should be established to choose the appropriate drug. ${ }^{7}$ Symptoms alone are notoriously unreliable, and the chest radiograph is of low diagnostic sensitivity. Some clinicians argue that detailed haemodynamic measurements are unnecessary, but they will admit to the value of using all available information from indwelling vascular catheters. ${ }^{11}$ In practice, the more deranged the haemodynamics the better seems the response to vasodilators, and patients with these features are more likely to have been intensively monitored.

Next, vasodilators have not been very successful in right heart failure, when the response is most unpredictable. ${ }^{12} \mathrm{~A}$ third perplexing problem is the response to withdrawal of vasodilators: three patients treated with prazosin for heart failure showed appreciable deterioration in their clinical condition after drug withdrawal, but the effect has not been described with other vasodilators. ${ }^{13}$ The final question, and probably the one of the greatest clinical importance, is whether vasodilators do maintain their effectiveness long term. The extent to which possible late decline in effectiveness is due to pharmacological tolerance to the drugs is debatable, but there is little good evidence that these agents prolong life, though the intolerable symptoms of heart failure may be remarkably improved in the short term. Enthusiasts ${ }^{14}$ may even see in vasodilators a more logical form of treatment than digitalis for less severely ill patients, and the high incidence of digitalis toxicity in such patients can be cited as a secondary justification for alternative treatment. Only time and further experience will provide the answer.

Alasdair Breckenridge

Professor of Clinical Pharmacology,

University of Liverpool,

Liverpool L69 3BX
'Sarnoff SJ, Farr HW. Spinal anesthesia in the treatment of pulmonary edema: a preliminary report. Anesthesiology $1944 ; 5: 69-76$.

${ }^{2}$ Arnold SB, Byrd RC, Meister W, et al. Long-term digitalis therapy improves left ventricular function in heart failure. $N \mathrm{Engl} f \mathrm{Med}$ $1980 ; 303: 1443-8$.

${ }^{3}$ Kirlin PC, Pitt B. Hemodynamic effects of intravenous prenalterol in severe heart failure. Am $\mathcal{F}$ Cardiol $1981 ; 47: 670-5$.

- MacCannell KL, McNay JL, Meyer MB, Goldberg LI. Dopamine in the treatment of hypotension and shock. N Engl $\mathcal{f}$ Med 1966;275: 1389-98.

5 Tuttle RR, Mills J. Dobutamine-development of a new catecholamine to selectively increase cardiac contractility. Circ Res 1975;36:185-96. ${ }^{6}$ Cohn JN, Franciosa JA. Vasodilator therapy of cardiac failure. (First of two parts.) $N$ Engl f Med 1977;297:27-31.

${ }^{7}$ Chatterjee K, Parmley WW. Vasodilator therapy for chronic heart failure. Annu Rev Pharmacol Toxicol 1980;20:475-512.

${ }^{8}$ Klausner SC, Ratshin RA, Tyberg JV, Lappin HA, Chatterjee K, Parmley WW. The similarity of changes in segmental contraction patterns induced by postextrasystolic potentiation and nitroglycerin. Circulation 1976;54:615-23.

${ }^{9}$ Parmley WW, Chuck L, Chatterjee K, et al. Acute changes in the diastolic pressure-volume relationship of the left ventricle. Eur $\mathcal{f}$ Cardiol 1974; 4, suppl:105-20.

${ }^{10}$ Cohn JN, Franciosa JA. Vasodilator therapy of cardiac failure. (Second of two parts.) N Engl f Med 1977;297:254-8.

11 Zelis R, Flaim SF, Moskowitz RM, Nellis SH. How much can we expect from vasodilator therapy in congestive heart failure? Circulation 1979; $\mathbf{5 9}: 1092-7$.

${ }^{12}$ Rutishauser $\mathrm{W}$, ed. The place of vasodilators in the long term treatment of intractable heart failure. Bern: Hans Huber, $1981: 82-99$.

${ }^{13}$ Hanley SP, Cowley A, Hampton JR. Danger of withdrawal of vasodilator therapy in patients with chronic heart-failure. Lancet 1980;i:735-6.

${ }^{14}$ Mason DT. Symposium perspective. Am $\mathcal{F}$ Med 1978;65:101-5.

\section{Laser treatment of portwine stains}

There are no reliable data on the incidence of the portwine naevus. Sadly, in most individuals the naevus shows little or no tendency to fade with time; indeed, with increasing age it usually becomes deeper red or purple.

Histological studies have shown that the portwine naevus is superficial and results from an aneurysmal dilatation and progressive ectasia of the cutaneous vascular plexus. ${ }^{1}$ The colour of the naevus seems to be influenced mostly by its red cell content. The typical adult portwine naevus is purple with large, blood-filled ectatic vessels, while the juvenile lesion is pink with small vessels relatively free of red cells. The pathogenesis of this (fortunately rare) vascular abnormality is unknown, but there seems to be no increased risk that the lesion will develop in the offspring of those affected.

No satisfactory treatment was available for the portwine stain until 1976, when Goldman described results obtained with the argon laser. ${ }^{2}$ This type of laser is effective because haemoglobin absorbs to some extent the blue-green laser light (wavelength $488-514 \mathrm{~nm}$ ), transforming energy into heat and coagulating blood vessels up to $0.5 \mathrm{~mm}$ in diameter. The final result is a diffuse, coagulative necrosis of the epidermis and papillary dermis. The adjoining relatively avascular skin appendages remain undamaged and are thus available for reconstruction of what is usually fairly normal epidermis. Histological studies have shown that the abnormal ectatic vessels of the portwine naevus are mostly confined to a $0.6 \mathrm{~mm}$ subepidermal zone ${ }^{1}$ and so are within the laser destruction range, which extends to the upper $1 \mathrm{~mm}$ of dermis. Though the number of new vessels may triple after treatment the number of erythrocytes contained in these smaller vessels is much reduced; the result is that the lesion that formerly appeared purple becomes much pinker. ${ }^{1}$

Many patients, including some with other cutaneous vascular lesions, have now been treated. ${ }^{3-7}$ Recent studies 